\title{
Semiologia das expressões corporais dos enfermeiros no cotidiano do serviço de emergência
}

\author{
Semiology of body expressions of nurses in the quotidian of the emergency service
}

Semiología de las expresiones corporales de los enfermeros en el cotidiano del servicio de emergencia

\section{Thiago Augusto Soares Monteiro da Silva', Maria José Coelho ${ }^{\mathrm{II}}$, Nébia Maria Almeida de Figueiredo ${ }^{\text {III }}$}

\begin{abstract}
Resumo: Objetivo: descrever a semiologia das expressões corporais e as tipologias de cuidados realizados pelos enfermeiros em emergência. Método: estudo qualitativo e exploratório, oriundo da coleta de dados por meio de imagens fílmicas, realizado com oito enfermeiros na emergência de um Hospital Universitário durante 24 dias. Resultados: identificou-se que os cuidados de Enfermagem na emergência apresentam uma natureza própria, discutida em 23 maneiras de cuidar: alerta; guerra; dinâmico; contínuo; contingencial; expressivo; multifaces; anônimo; admissional; registrado; conexões; diurno; noturno; passagem de plantão; corpo transformado; eletrônico; microespaço, à margem social, da população de rua, mural, perto/distante, corpo (semi)morto, dos profissionais do cuidado. Considerações finais: o estudo em tela permitiu identificar, por meio das imagens, a natureza dos cuidados de Enfermagem na emergência.
\end{abstract}

Descritores: Cuidados de enfermagem; Enfermagem em emergência; Comunicação não verbal

\begin{abstract}
Aim: to describe the semiology of body expressions and the typologies of care performed by emergency nurses. Method: qualitative and exploratory study arising from data collection by means of recorded images, performed with eight nurses in the emergency unit of a University Hospital, during 24 days. Results: it was identified that Nursing care in emergency units has a nature of its own, discussed in 23 ways of caring: alert; war; dynamic; continuous; contingency; expressive; multifaceted; anonymous; admission; registered; connections; daily, nightly; shift change; transformed body; electronic; micro-space; socially aside; of street population; mural; near/far; (half-)dead body; of care professionals. Final considerations: the present study allowed the identification, through the images, of the nature of Nursing care in the emergency room.
\end{abstract}

Descriptors: Nursing care; Emergency nursing; Non-verbal communication

\footnotetext{
I Enfermeiro, Doutor em Enfermagem pela Escola de Enfermagem Anna Nery (EEAN) da Universidade Federal do Rio de Janeiro (UFRJ). Mestre em Enfermagem pela Universidade Federal do Estado do Rio de Janeiro (UNIRIO), Pós graduado em Enfermagem em Oncologia Clínica pela Universidade Veiga de Almeida. Professor do curso de Enfermagem da Universidade de Vassouras. Vassouras, Rio de Janeiro, Brasil, e-mail: thiagoams@bol.com.br; https://orcid.org/0000-0001-6870-5101

II Enfermeira, Doutora e Mestre em Enfermagem pela Escola de Enfermagem Anna Nery da Universidade Federal do Rio de Janeiro (EEAN/UFRJ). Rio de Janeiro, Rio de Janeiro, Brasil, e-mail: zezecoelho@yahoo.com.br; https://orcid.org/0000-0001-6579-1796

III Enfermeira, Doutora e Mestre em Enfermagem pela Escola de Enfermagem Anna Nery da Universidade Federal do Rio de Janeiro (EEAN/UfRJ). Professora emérita da Escola de Enfermagem Alfredo Pinto da Universidade Federal do Estado do Rio de Janeiro (EEAP/UNIRIO). Rio de Janeiro, Rio de Janeiro, Brasil, e-mail: nebia43@gmail.com; https://orcid.org/0000-0003-0880-687X
} 
Semiologia das expressões corporais dos enfermeiros no cotidiano do serviço de emergência 12

Resumen: Objetivo: describir la semiología de las expresiones corporales y las tipologías de cuidados realizados por enfermeros en emergencia. Método: estudio cualitativo y exploratorio, realizado a partir de la recolección de datos por medio de imágenes grabadas, con ocho enfermeros en la emergencia de un Hospital Universitario, durante 24 días. Resultados: se identificó que los cuidados de Enfermería en la emergencia presentan una naturaleza propia, discutida en 23 maneras de cuidar: alerta; guerra; dinámico; continuo, de contingencia; expresivo; multifocal; anónimo, de lo que está al margen social; de población desasistida; mural; cercano/lejano; del cuerpo (semi)muerto; de los profesionales; de admisión; registrado; de conexiones; diurno; nocturno; en cambio de turno; del cuerpo transformado; electrónico; del microespacio. Consideraciones finales: el estudio en pantalla ha permitido identificar, por medio de las imágenes, la naturaleza de los cuidados de Enfermería en la emergencia.

Descriptores: Cuidados de enfermería; Enfermería en emergencia; Comunicación no verbal.

\section{Introdução}

O serviço de emergência representa um componente fundamental para o atendimento de saúde da população. Localizado frequentemente no primeiro andar dos Hospitais Gerais ou em locais no nível da rua, permite fácil acesso à população e permanece aberto 24 horas por dia. Portanto, constituiu-se em uma porta de entrada para o atendimento da população com situações de emergência e urgência para clientes desgarrados do serviço primário ou ambulatorial e com necessidades sociais. ${ }^{1}$

Sabe-se que o aumento na demanda dos atendimentos na unidade de emergência é decorrente do processo de transição demográfica que o Brasil está passando, uma vez que temse no cenário atual o avanço da expectativa de vida e a redução nas taxas de mortalidade e natalidade, o que acarreta um aumento da população idosa e, consequentemente, das doenças crônico-degenerativas, que elevam a procura pelos atendimentos de emergência. ${ }^{1-2}$ Percebe-se também o aumento na criminalidade, da violência urbana e de acidentes de trânsito, fatores que contribuem para a superlotação dos serviços de emergência. ${ }^{1-2}$

Diante do exposto, compreende-se que o setor de emergência se configura como um elo entre a população e o atendimento de saúde, e que as situações de emergência ocorrem cotidianamente, acometendo crianças, adolescentes, idosos, mulheres e homens, independente dos fatores socioculturais, econômicos ou espirituais. Isto faz com que o enfermeiro tenha de 
desenvolver agilidade, criatividade, humanismo e que se utilize das tecnologias disponíveis para realizar os cuidar/cuidados de Enfermagem na clientela. ${ }^{3-4}$

No cotidiano do serviço de emergência, os enfermeiros têm como objeto de trabalho o cuidar e os cuidados ao cliente, à família e à comunidade e a gerência do cuidado para tratar situações emergenciais, reduzir as de risco, a fim de evitar a morte. ${ }^{4}$ Mesmo considerando-se a emergência como um local caótico e desordenado, esta apresenta em seu núcleo uma ordem e uma sequência lógica em seus passos. ${ }^{5-6}$ É a desordem buscando uma ordem que é a manutenção da vida. ${ }^{3}$ Assim, o enfermeiro possui as suas maneiras específicas de cuidar, que podem ser invisíveis no cotidiano do setor de emergência. ${ }^{5-6}$

Mediante o exposto, emergiram como questões norteadoras: quais as expressões corporais adotados pelos enfermeiros durante os cuidados de enfermagem ao cliente no setor de emergência? qual o cuidar e que tipos de cuidados são prestados numa situação de emergência? e qual a especificidade da ação de cuidar?

Em vista destes questionamentos, o objeto da presente investigação é o cuidar/cuidados de enfermagem em unidade de emergência, em face das especificidades e/ou aspectos distintivos no cotidiano da prática assistencial. Outro ponto importante é o resultado da pesquisa como uma contribuição significativa para a construção do conhecimento relativo à área de enfermagem em emergência.

Desse modo, o estudo teve como objetivos: descrever a semiologia das expressões corporais e as tipologias de cuidados realizados pelos enfermeiros em emergência.

\section{Método}

Estudo exploratório sobre as maneiras de cuidar/cuidados de Enfermagem no setor de emergência, sendo a abordagem qualitativa. Trata-se de estudo epistemológico sobre o cuidar e os cuidados de Enfermagem no processo saúde-doença, levando em consideração as ações de 
Semiologia das expressões corporais dos enfermeiros no cotidiano do serviço de emergência $\mid 4$

cuidar e os aspectos práticos de prestar os cuidados, ${ }^{7}$ assim validando e ampliando as maneiras específicas de cuidados de Enfermagem no serviço emergência.

O cenário foi o setor de emergência de um Hospital Universitário (HU) no interior do estado do Rio de Janeiro. Nessa perspectiva, solicitou-se a autorização por escrito a Direção de ensino do HU, oportunidade em que foi autorizada a coleta de dados.

Os participantes foram oito enfermeiros que atuavam nos plantões diurnos e noturnos, os quais foram informados sobre a pesquisa por meio do Termo de Consentimento Livre e Esclarecido (TCLE) e concordaram e assinaram o termo de cessão e de direito de imagem cedendo o uso para os pesquisadores. Os participantes foram selecionados segundo os critérios de inclusão: ser enfermeiro atuante no setor de emergência no mínimo há seis meses, sendo excluídos profissionais em período de férias ou em licença saúde durante a coleta de dados.

O serviço conta com dois enfermeiros por plantão, totalizando oito enfermeiros. Ressaltase que dos oito sujeitos, quatro ficavam responsáveis pelo serviço de acolhimento com classificação de risco, ou seja, um enfermeiro por plantão diurno e noturno em plantões pares e ímpares, atendendo todos os clientes que dessem entrada no serviço de emergência e auxiliavam, quando possível, os atendimentos de emergência e urgência.

Quanto aos outros quatro enfermeiros, identificou-se que eles realizavam os cuidados diretos e indiretos de clientes com quadros de emergência, urgência, pouco urgentes e não urgentes, e pelo gerenciamento de Enfermagem do plantão. Ressalta-se que os plantonistas noturnos, além de realizarem as atividades mencionadas anteriormente, eram responsáveis pelos cuidados de 195 clientes internados em outros setores como clínica médica feminina e masculina, clínica cirúrgica feminina e masculina, ginecologia e obstetrícia, pediatria, apartamentos e centro cirúrgico. 
Foi utilizado como instrumento para a coleta de dados uma câmera filmadora móvel Full HD e o diário de campo com registros das observações não participantes do pesquisador nas horas concomitantes às filmagens na emergência.

Realizou-se o reconhecimento do cenário e da equipe de Enfermagem e, posteriormente, foi feita a explicação para os enfermeiros dos objetivos estabelecidos para a pesquisa e a técnica de coleta de dados, sendo entregue o TCLE e o termo de cessão de direito de imagens para apreciação. Após as assinaturas dando o consentimento, foram iniciadas as videogravações e as observações com registros em diário de campo.

Após a aprovação do Comitê de ética procedeu-se a coleta de dados por meio de filmagens realizadas entre novembro e dezembro de 2013 durante 24 dias. A escolha do período de coleta de dados se deu em conformidade com a disponibilidade do pesquisador para permanência no setor de emergência para coleta de dados. Destaca-se que realizou-se 288 horas de observações participantes dos cuidados de enfermagem desempenhados pelos enfermeiros no setor de emergência registrados em um diário de campo.

Durante a coleta de dados, a câmera filmadora móvel foi mantida em armários ou em mesas das salas vermelhas, amarelas, verde, a Sala de Acolhimento com Classificação de Risco ou no Posto de Enfermagem.

Foi realizada a coleta dos registros dos atendimentos no Boletim de Atendimento Médico (BAM) entre janeiro e dezembro de 2014 com o intuito de compreender o fluxo de atendimentos do cenário de estudo.

Após registradas e armazenadas em Hard Disck (HD), as imagens foram vistas, revistas e procedeu-se com a decupagem, que consistiu em avaliar as imagens, plano a plano, sendo obtidos 4790 fotogramas correspondente às 15 horas e 38 minutos de videogravação.

Salienta-se que durante a coleta de dados, outros sujeitos estiveram presentes nas gravações, sendo estas imagens excluídas ou preservadas por uma tarja preta após a decupagem 
Semiologia das expressões corporais dos enfermeiros no cotidiano do serviço de emergência $\mid 6$

e análise. A medida foi necessária por serem os sujeitos-objeto do estudo os enfermeiros atuantes no serviço de emergência cenário de pesquisa.

As imagens foram selecionadas conforme a semelhança da ação e natureza dos cuidados, tendo por critério a repetição de gestualidade dos enfermeiros. Observou-se: a) A posição dos enfermeiros em relação ao cliente, b) o cuidado que estavam realizando, c) o local que se encontravam no momento da videogravação, d) as expressões faciais e gestualidade corporal e e) os elementos presentes na imagem considerando o cliente, os materiais, os medicamentos, os documentos, outros profissionais.

Foi procedida a análise semiótica de cada fotograma, identificando dados da comunicação não-verbal, que incluem a proxêmica, tacésica, cinésica e paralinguagem. É importante destacar que pela grande intensidade de ruídos no ambiente, a análise da paralinguagem não foi realizada neste estudo. Posteriormente, procedeu-se com a análise das imagens e dos dados do diário de campo, à luz do referencial teórico sobre cuidar/cuidados de Enfermagem em emergência. ${ }^{5}$

Adotou-se no estudo como pontos de referência para o cálculo da distância na análise das imagens, o posicionamento do enfermeiro sujeito-objeto do estudo em relação ao cliente em momentos de cuidados no serviço de emergência, sendo utilizado como referencial a proxêmica. ${ }^{8}$ A análise das distâncias e proximidades adotadas pelos profissionais com relação ao cliente permite identificar como ocorre o cotidiano de cuidar/cuidados realizados pelos enfermeiros na unidade de emergência, fornecendo informações importantes sobre os tempos e movimentos e os tipos de cuidar/cuidados realizados pelos mesmos.

O estudo foi submetido à aprovação do Comitê de Ética em Pesquisa da Universidade Federal do Estado do Rio de Janeiro (CEP-UNIRIO), sendo aprovado no dia 31 de outubro de 2013, sob o protocolo $\mathrm{n}^{\circ}$ 436.108. Ressalta-se que a pesquisa foi conduzida de acordo com os padrões éticos exigidos pela resolução 466/2012. 


\section{Resultados e discussão}

O ambiente do serviço de emergência apresenta $239,28 \mathrm{~m}^{2}$ distribuídos entre recepção/sala azul, sala de acolhimento com classificação de risco, duas salas vermelhas, uma sala verde, duas salas amarelas, uma sala de sutura, um consultório de clínica médica, um consultório de pediatria e um consultório de ginecologia e obstetrícia.

Conta com um posto de Enfermagem conforme preconizado para a arquitetura hospitalar, pois os doentes mais graves devem ser colocados o mais próximo possível do posto de Enfermagem ou defronte. ${ }^{9}$ Essa estrutura previne o aumento do percurso realizado pela Enfermagem e traz maior qualidade para os cuidados, pois ajuda a promover menor desgaste físico da equipe de Enfermagem e economiza o tempo para realizar os cuidados diretos na emergência. ${ }^{9}$

O serviço de emergência utiliza, desde 2012, o protocolo adaptado ${ }^{10}$ para acolhimento com classificação dos clientes, sendo padronizado na instituição o uso das cores vermelha, amarela, verde e azul, que representam a classificação dos clientes. Esta classificação é realizada pelos enfermeiros em conformidade com as prioridades de atendimento. ${ }^{11}$

No ano de 2014, foram prestados cuidados de Enfermagem a 59.196 usuários, sendo deste total $81 \%$ (31.622) classificados como clientes com casos pouco urgentes, $11 \%$ (23.219) foram casos de urgência, 4\% (4.083) casos não urgentes e 1\% (272) casos de emergência.

Observa-se que, apesar do serviço de acolhimento com classificação de risco já estar organizado e funcionando neste hospital, a população ainda apresenta uma cultura de utilizar o serviço de emergência como porta de entrada para os serviços de saúde. ${ }^{12-13}$ Diante da superlotação, os enfermeiros podem sofrer maior desgaste físico e mental, o que pode contribuir negativamente para a qualidade dos cuidados pretados.

\section{Semiologia das expressões corporais dos enfermeiros}


Semiologia das expressões corporais dos enfermeiros no cotidiano do serviço de emergência $\mid 8$

Quanto à análise dos dados proxêmicos em cada fotograma, identificou-se que em $61 \%$ (2912) os enfermeiros encontravam-se a uma distância pública do cliente, 36\% (1713) em uma distância íntima, 2\% (107) em uma distância pessoal e 1\% (58) em uma distância social.

Após a decupagem das imagens, 8\% (375) mostravam o enfermeiro apresentando-se aos clientes e tocando-os, forma de comunicação associada à proxêmica - distância íntima, pois para estabelecer o toque é necessário estar próximo.

As imagens permitiram identificar os enfermeiros tocando os clientes em situações diferentes na emergência: exame físico, curativo, verificação de sinais vitais, mudança de leito, cateterismo nasogástrico, massagem cardíaca, cateterismo vesical, administração de medicamentos, higiene íntima, punções venosas, toque para confortar.

Os registros fílmicos realizados permitiram a identificação de um movimento cinésico mais frequente dos enfermeiros que é a atenção. O enfermeiro demonstrou estar interessado no cliente e família ou em medicações, monitores, respiradores, é visível a inclinação e tensão do corpo em direção ao cliente ou objetivo, mostrando abertamente o seu interesse.

Esse é um gesto visto em 69\% (3301) dos fotogramas, os enfermeiros encontram-se inclinando o corpo para próximo do cliente ou objeto observado e mantendo contato visual direto, indicando assim uma atenção constante ao cuidado direto ou indireto prestado por eles na emergência.

Ao analisar a semiologia das expressões corporais dos enfermeiros no serviço de emergência, percebeu-se que os resultados corroboram a tese de que o corpo do enfermeiro é instrumento da ação do cuidado. ${ }^{14}$

A comunicação é um instrumento básico do cuidado de Enfermagem que permite o enfermeiro interagir, estabelecer uma relação de ajuda e realizar o cuidado de Enfermagem. No serviço de emergência é essencial que o enfermeiro fique atento aos aspectos não verbais, pois 
muitos clientes podem não apresentar condições favoráveis para a comunicação verbal. ${ }^{15}$ Assim, entende-se que a comunicação é uma questão fundamental no cuidado de Enfermagem em emergência e proporciona realizar o cuidado de Enfermagem em conformidade com as necessidades do cliente para o momento. ${ }^{16}$

A comunicação não verbal compreende aos dados proxêmicos, cinésicos, tacésicos e paralinguagem. Os dados proxêmicos consistem no uso que o homem faz do espaço em torno de si; de que maneira, ao utilizá-lo, pode comunicar certas mensagens e como reage a isso.$^{8-17}$ As distâncias mantidas durante uma interação entre indivíduos são divididas em quatro distâncias: íntima, pessoal, social e pública.

A distância íntima é dividida em fase próxima e fase afastada, varia de 15 a $45 \mathrm{~cm} \cdot{ }^{8-17}$ Essa é a distância que o ser humano normalmente mantém das pessoas em quem ele confia, como familiares e amigos. ${ }^{8-17} \mathrm{Na}$ emergência, a distância íntima é mantida quando o enfermeiro realiza cuidados diretos, examina e admite o cliente, mantendo-se nessa distância até a estabilização do quadro de emergência.

A distância pessoal é dividida em fase próxima, que varia de 50 a $80 \mathrm{~cm}$, e a fase afastada, que varia de $80 \mathrm{~cm}$ a $1,20 \mathrm{~m} \cdot \cdot^{8-17}$ Geralmente, as pessoas que adentram esse espaço são conhecidas..$^{8-17} \mathrm{O}$ enfermeiro observa o cliente, avalia os dados no monitor cardíaco, realiza uma observação geral da unidade em que o cliente está e utiliza estas informações para reorganizar o leito e o carrinho de reanimação cardiopulmonar.

A distância social é dividida em fase próxima, que varia de $1,20 \mathrm{~m}$ a 2,10m, e fase afastada, que varia de 2,10 a 3,50m. ${ }^{8-17}$ Geralmente, a textura da pele, o cabelo, a condição dos dentes, das roupas são visíveis facilmente, porém perceber a respiração, sentir o calor e o odor do corpo da outra pessoa não é mais possível. ${ }^{8-17}$ Nessa distância o enfermeiro observa o cliente, o monitor cardíaco, o ambiente em que o cliente se encontra, e é uma zona em que realiza a organização e a reorganização do cenário de cuidados. 
Semiologia das expressões corporais dos enfermeiros no cotidiano do serviço de emergência | 10

A distância pública é dividida em fase próxima, que varia de $3,50 \mathrm{~m}$ a $7,50 \mathrm{~m}$, e fase afastada, que varia de 7,50m ou mais. ${ }^{8-17}$ Nessa distância, as pessoas estão situadas fora do círculo de envolvimento. ${ }^{8-17}$ São realizados os registros no boletim de atendimento médico, livros de ocorrências e gerencia o setor, reorganiza materiais e medicamentos.

Os distanciamentos e proximidades do corpo do enfermeiro para o corpo do cliente integram o cotidiano de cuidar/cuidados de Enfermagem. Observou-se, no caso, que 61\% dos enfermeiros estavam a uma distância pública, mas os enfermeiros permanecem realizando cuidados como de alerta ao organizar e reorganizar o setor para receber outros clientes que podem chegar de forma momentânea, realizam cuidados de conexão ao realizar ligações para outros setores, como serviço social, psicologia, serviço de imagem, para que esses serviços possam chegar até o cliente que se encontra no serviço de emergência.

O afastamento é necessário para dar sequência a outros cuidados e para proporcionar privacidade ao cliente que passou por uma situação estressante devido à condição de emergência. Em muitas situações, há exposição corporal e são realizados vários procedimentos invasivos. Percebe-se que 36\% dos enfermeiros encontraram-se a uma distância íntima, realizando cuidados diretos aos clientes ao executar procedimentos invasivos.

As ações proxêmicas demonstram que o cuidado de enfermagem pressupõe aproximação corporal, ou seja, o cuidado só pode ser demonstrado e praticado de forma interpessoal. ${ }^{18}$ É necessário proximidades e distâncias para que os cuidados diretos e indiretos aconteçam e o enfermeiro utiliza seu corpo como instrumento do cuidado, observando, ouvindo, tocando e falando com o cliente para poder sistematizar o cuidado de Enfermagem.

A tacésica consiste no uso do tato, como por exemplo, na verificação da pressão, no toque. O toque torna-se intermédio ou intermediador na relação enfermeiro-cliente que se encontra no cotidiano de cuidar/cuidados de Enfermagem. ${ }^{19}$ Através da intensidade do toque do enfermeiro, são gerados estímulos sensoriais no corpo do cliente, causando desconforto ou 
prazer. ${ }^{20}$ No estudo, identificou-se que os enfermeiros encostam nos clientes para realizar vários procedimentos e realizam o toque para confortá-los.

A cinésica consiste nos gestos corporais, movimentos de membros, expressões faciais, meneios de cabeça. É a linguagem corporal. ${ }^{21-22}$ Neste estudo, percebe-se que os enfermeiros permanecem com contato visual constante com o cliente em atendimento ou com os materiais e objetos organizados ou preparados para permitir o cuidado do cliente. Assim, é possível estabelecer o vínculo necessário à proximidade e confiança para o cuidar/cuidados de Enfermagem. ${ }^{21}$ Esse gesto demonstra o estado de alerta que os enfermeiros mantêm na realização dos cuidados de Enfermagem.

Com base na análise das imagens fílmicas, encontrou-se expressões de organização do trabalho dos enfermeiros que têm um valor de conteúdo e de poder das imagens para os dias atuais e para a Enfermagem, em particular, indicando que ela tem maneiras de fazer como profissão do campo de saúde e de seu campo específico de trabalho.

\section{Tipologia de cuidar/cuidados realizados pelos enfermeiros em emergência}

Mediante o reconhecimento da subjetividade/objetividade no cuidar/cuidado desempenhado pelo enfermeiro, foi importante adotar uma nomenclatura específica, proporcionando a criação de um paradigma de cuidar realizado pelo enfermeiro. Essa nomemclatura necessitava incluir o ser humano em seus aspectos biopsicossocioculturais e econômicos, e que se distanciasse do modelo predominantemente biomédico, mecanicista e centrado nas respostas orgânicas. ${ }^{5}$

Ressalta-se que foram reafirmados os 14 tipos de cuidar/cuidados ${ }^{5}$ e identificou-se outros nove tipos totalizando 23 tipos de cuidar/cuidados de Enfermagem em emergência que são:

Cuidar/cuidado de alerta - É o cuidar/cuidado em que os enfermeiros se mantêm vigilantes todo tempo das 12 horas de plantão, aguardando outro cliente chegar, ou é o cuidado 
Semiologia das expressões corporais dos enfermeiros no cotidiano do serviço de emergência | 12

a um cliente que é reclassificado e exige atendimento imediato e de forma intensa., ${ }^{52}$ Visível na coleta de dados para o histórico de enfermagem na sala de Acolhimento com Classificação de Risco ou nas salas vermelhas e amarelas e vai até a organização e reorganização do ambiente após a estabilização ou óbito de um cliente.

Cuidar/cuidado de guerra - são os cuidados diretos de Enfermagem realizados aos clientes em situações agudizadas, necessitando que o enfermeiro acolha o cliente, classifique o risco, estabeleça diagnósticos de Enfermagem que precisam de intervenções rápidas. ${ }^{5,22}$ Os enfermeiros nesse cuidar/cuidados permanecem em observação dos clientes já estabilizados com quadros graves que podem culminar em uma mudança repentina e necessitem de novos cuidados até nova estabilização do quadro.

Cuidar/cuidado contingencial - compreende os cuidados diretos realizados às vítimas de trauma, ou em situações clínicas em estado grave, que precisam de suporte avançado de vida para serem retirados do estado de risco iminente de morte. Os enfermeiros utilizam de tecnologias do cuidar como um ato concreto. ${ }^{5}$

Cuidar/cuidado contínuo - realizado em todos os plantões corresponde aos cuidados de Enfermagem, com o objetivo de dar continuidade aos iniciados pela equipe do plantão anterior. ${ }^{5,22} \mathrm{O}$ serviço de emergência em muitas situações se transforma em uma unidade de cuidados intensivos de forma improvisada para manter clientes em estado grave aguardando vaga no Centro de Terapia Intensiva ou transferência para outro hospital com vaga para internação. Outros clientes são mantidos internados nas salas amarelas aguardando vagas nas enfermarias e necessitam de cuidados diários. Consiste também na reposição de materiais e medicamentos para permitir a continuidade dos cuidados de Enfermagem., ${ }^{5,22}$

Cuidar/cuidado dinâmico - são cuidados diretos e indiretos de Enfermagem realizados de forma simultânea, quando chegam clientes classificados como vermelhos, após um trauma ou situação clínica grave, enquanto outros clientes classificados como amarelos ou verdes recebem 
alta após a realização de exames e administração de medicamentos. ${ }^{5,22}$ O cuidar/cuidado é realizado de forma intensa durante um contato rápido, pois vários clientes permanecem pouco tempo no setor.

Cuidar/cuidado expressivo - os enfermeiros utilizam a comunicação verbal e não-verbal para identificar o que parece inicialmente invisível no cotidiano de cuidados na emergência., , $^{22}$ O corpo do enfermeiro é o seu instrumento e ação do cuidado, em sintonia com os corpos expressivos dos clientes, quando aparecem os sentimentos que os profissionais têm durante os cuidados.

Cuidar/cuidado anônimo - compreende a identificação de clientes que são admitidos no setor de emergência sem documentos de identidade, inconscientes ou desorientados. ${ }^{5,22}$ É necessário o contato com o serviço social com o intuito de resgatar a identidade do cliente.

Cuidar/cuidado multifaces - compreende os cuidados aos clientes estrangeiros, sendo necessário o respeito aos aspectos culturais, sociais, econômicos e políticos. ${ }^{5}$ Compreende também os cuidados aos clientes com doenças infecto-contagiosas ou crônicas que sofreram um trauma, sendo necessário identificar a gravidade do caso para reduzir o risco de transmissão de doenças infecto-contagiosas para outros clientes e para a equipe multiprofissional atuante no setor de emergência. ${ }^{5}$

Cuidar/cuidado ao que se encontra à margem social - são os cuidados diretos e indiretos realizados aos perpetradores de violências que estão acautelados, que pertencem ao tráfico de drogas feridos por arma de fogo ou que são apreendidos com posse ou após ingestão de drogas. ${ }^{5}$ No setor de emergência cenário deste estudo o Boletim de Atendimento Médico (BAM) recebe um carimbo de ocorrência policial. Esse cuidado mostra a necessidade de maior aprofundamento da Enfermagem Forense no Brasil.

Cuidar/cuidado da população de rua - é o cuidado social, de educação e de saúde pública, que compreende o acolhimento aos clientes sem residência fixa, que buscam comida e abrigo na unidade de emergência. ${ }^{5}$ Em muitos casos, é necessário o contato com o serviço social para 
Semiologia das expressões corporais dos enfermeiros no cotidiano do serviço de emergência | 14

encaminhamento desses sujeitos a abrigos. Esse cuidado transcende a técnica e permite identificar a enfermagem como uma prática social.

Cuidar/cuidado mural - são os cuidados indiretos, realizados através de observações afixadas em murais, quadros, escalas, fluxogramas, proporcionando que os profissionais da equipe de Enfermagem sejam orientados quanto às condutas necessárias a serem adotadas de forma segura, rápida, com lógica e coerência. ${ }^{5,22}$

Cuidar/cuidado perto/distante - são os cuidados diretos realizados em distância íntima e pessoal, quando é necessário tocar o cliente, puncionar acesso venoso periférico, cateterismo nasogástrico, vesical, curativos. Os cuidados indiretos são realizados nas distâncias social e pública, para providenciar materiais, medicamentos, registros dos cuidados. ${ }^{5}$ Mesmo distantes, os enfermeiros permanecem em situação de alerta.

Cuidar/cuidado do corpo (semi)morto - esse cuidado envolve o direito do ser humano de ter uma morte digna ou serena, uma vez que oferece conforto, acolhimento, atenção. ${ }^{5}$ Compreende os cuidados diretos com o corpo, as orientações aos familiares, o encaminhamento do corpo ao necrotério.

Cuidar/cuidado dos profissionais do cuidado - direcionado aos profissionais da equipe de Enfermagem atuantes no setor de emergência que vivenciam constantemente angústias, estresses, medos, tristezas além da possibilidade de contato com clientes com doenças infectocontagiosas. $^{5}$

Cuidar/cuidado Admissional - tem como princípio o acolhimento, a acomodação, proporcionando conforto aos clientes e seus familiares. Segue uma sistematização para melhorar a qualidade da assistência, proporcionando o cuidado rápido aos clientes em situações de maior gravidade. Assim, minimiza o estresse dos clientes que aguardam o atendimento, além de contribuir para a gerência dos cuidados prestados..$^{5,22}$ 
Cuidar/cuidado registrado - tem como finalidade o registro de informações dos clientes, como a anamnese, o diagnóstico, as intervenções e os resultados de enfermagem, ações planejadas, tais como descrição de pertences, internações, transferências, registros de óbitos. Esse cuidado também envolve os registros referentes à necessidade de reposição de materiais, medicamentos e controle de psicotrópicos, fornecendo subsídios para a resolução de problemas durante os plantões diurnos e noturnos. ${ }^{5}$

Cuidar/cuidado de Conexões - é através do enfermeiro que os demais serviços são organizados e articulados para chegarem até o cliente no setor de emergência, tais como: Laboratório de Análises Clínicas; Radiologia; Centro de Terapia Intensiva; Centro Cirúrgico; Central de Material e Esterilização; Serviço Social; Serviço de Nutrição; Psicologia.5,22

Cuidar/cuidado Diurno - compreende a realização dos cuidados diretos e o planejamento e a execução de cuidados indiretos pela manhã, é necessário reorganizar o setor de emergência. Esses cuidados ocorrem em meio ao grande fluxo de passagem de clientes, profissionais da equipe de Enfermagem, médicos, psicólogos, assistentes sociais, acadêmicos. ${ }^{5}$ Esse cuidado tem como aspecto distintivo a dinâmica e a agilidade de reorganizar o setor para permitir o cuidado dos próximos clientes que podem chegar a qualquer instante, identificandose mais ruídos e maior número de atendimentos.

Cuidar/cuidado Noturno - são realizados os cuidados diretos de continuidade ao plantão diurno, a reorganização do setor de emergência. Nesse cuidar/cuidado, é identificado o silêncio prolongado e menor número de atendimentos. Os profissionais da equipe de Enfermagem sofrem alteração no ritmo circadiano. Durante a noite; os enfermeiros se tornam elos entre o cliente e o médico plantonista. ${ }^{5}$

Cuidar/cuidado na Passagem de plantão - são cuidados diretos e indiretos realizados após o término do plantão diurno para o plantão noturno e vice-versa. Observa-se que a enfermagem permanece 24 horas em estado de alerta para manter a continuidade dos cuidados realizados aos clientes em situações de emergência. ${ }^{5,23}$ 
Semiologia das expressões corporais dos enfermeiros no cotidiano do serviço de emergência | 16

Cuidar/cuidado do corpo transformado - os cuidados de Enfermagem no serviço de emergência modificam temporariamente o corpo do cliente, sendo necessário colocar eletrodos no tórax do cliente para monitorar seus sinais vitais, cateterismos e compreende também o cuidado ao cliente que sofreu transformações no corpo decorrentes de amputação traumática, traumatismo craniano, edemas, feridas causadas por arma branca ou de fogo. ${ }^{5}$

Cuidar/cuidado eletrônico - consiste no cuidado indireto de Enfermagem que apoia o cuidado registrado. No serviço de emergência, os enfermeiros registram os dados da anamnese, solicitam materiais e medicamentos, realizam os levantamentos estatísticos sobre os atendimentos da unidade através de softwares, podem facilitar o gerenciamento dos cuidados de Enfermagem. ${ }^{5}$

Cuidar/cuidado do microespaço - consiste na desinfecção do leito previamente utilizado para permitir que um outro cliente o utilize. Durante as 24 horas do cotidiano de cuidar/cuidados, passam no serviço de emergência clientes com floras bacterianas diversas, sendo esse cuidado necessário à manutenção da segurança do cliente. ${ }^{24}$

\section{Considerações finais}

Os cuidados realizados pelos enfermeiros no serviço de emergência apresentam 23 maneiras de fazê-lo, que se interligam para permitir retirar o cliente de situações de agravamento ou de risco iminente de morte.

A comunicação verbal e não-verbal consiste em componentes fundamentais do cuidar/cuidados de Enfermagem na emergência, pois os enfermeiros precisam adotar distâncias e proximidades para cuidar, tocam para realizar procedimentos e para confortar e mantêm-se o tempo todo em estado de alerta para as repentinas mudanças que possam ocorrer.

Os estudos sobre a tipologia de cuidar/cuidados desempenhados pelos enfermeiros em emergência são incipientes e carecem de maior aprofundamento, principalmente no que tange a 
técnica de coleta de dados utilizando a videogravação do cenário do serviço de emergência. Percebe-se que esse estudo pode ser considerado uma experiência primeira que pode gerar possibilidades de novas pesquisas e poderá permitir maior aprofundamento da nomenclatura de cuidar/cuidados realizados pelos enfermeiros na unidade de emergência.

Ressalta-se que as imagens obtidas na técnica de videogravação podem permitir aos enfermeiros se auto-avaliarem durante o cotidiano de cuidar/cuidados de Enfermagem, contribuindo assim para repensar sobre a sua comunicação não verbal no cenário de cuidados, visando desempenhar o cuidado aos clientes de forma eficiente, efetiva e com criticidade. Assim, identifica-se que o uso dessa técnica pode contribuir para a pesquisa, ensino, assistência e gerência realizada pelos enfermeiros, pois permite a análise criteriosa dos tempos e movimentos dos profissionais e acadêmicos de Enfermagem, podendo contribuir para reavaliar como o cuidado acontece e buscar mudanças no cotidiano de cuidar/cuidados.

O estudo apresentou como limitações a utilização de apenas uma câmera filmadora móvel para a coletada de dados e apenas um pesquisador para observar e realizar as filmagens. Seria necessário, pelo menos, mais duas câmeras e mais dois pesquisadores. Este estudo necessita ser replicado em outros serviços de emergência para proporcionar a ampliação dos seus resultados.

\section{Referências}

1. Oliveira ANS, Lima KSBF, Moura LA, Mendes RNC, Oliveira JG, Moura JG. The epidemiological clinical profile of users of the emergency network in the countryside of Pernambuco. Rev Pesqui Cuid Fundam [Internet]. 2013 [acesso em 2017 abr 10];5(2):3601-7. Disponível em: http://www.seer.unirio.br/index.php/cuidadofundamental/article/view/2006

2. Schimidt TCG, Silva MJP. Proxêmica e cinésica como recursos comunicacionais entre o profissional de saúde e o idoso hospitalizado. Rev Enferm UERJ [Internet]. 2012 [acesso em 2017 abr 10];20(3):349-54. Disponível em: http://www.facenf.uerj.br/v20n3/v20n3a12.pdf

3. Figueiredo NMA. Cuidando em emergência. São Caetano do Sul: Difusão; 2004.

4. Figueiredo NMA, Vieira AAB, organizadores. Emergência: atendimento e cuidados de enfermagem. São Caetano do Sul: Yendis; 2006.

5. Coelho MJ. Maneiras de cuidar em enfermagem. Rev Bras Enferm. 2006;59(6):745-51. 
6. Santos DS, Ribeiro HCTC, Araujo MT, Alves M, Carrieri AP. What is really important to think about everyday life in nursing?: na integrative review. Rev Enferm UFPE [Internet]. 2014 [acesso em 2017 nov 25];8(10):3502-15.

Disponível

em:

http://www.revista.ufpe.br/revistaenfermagem/index.php/revista/article/view/6008/pdf_6317

7. Carvalho V. Sobre construtos epistemológicos nas ciências: uma contribuição para enfermagem. Rev Latinoam Enferm. 2003; 11(4):420-8.

8. Hall ET. A dimensão oculta. São Paulo: Martins Fontes; 2005.

9. Goés RD. Manual prático de arquitetura hospitalar. 2ª ed. São Paulo: Blucher; 2011.

10. Brasil. Ministério da Saúde. Secretaria de Assistência à Saúde. Portaria GM/MS n. 2048, de 05 de novembro de 2002: regulamento técnico dos sistemas estaduais de urgência e emergência [Internet]. 2002 [acesso em 2017 nov 25]. Disponível em: http://www.saude.mg.gov.br/images/documentos/portaria_2048_B.pdf

11. Feitosa MM, Silva ICG, Costa RTS, Andrade ICF, Souza Neto VL, Silva RAR. Acolhimento com classificação de risco na unidade de pronto atendimento: um relato de experiência. Rev Enferm UFSM [Internet]. 2017 [acesso em 2017 abr 06];7(1):136-43. Disponível em: https://periodicos.ufsm.br/reufsm/article/view/17173/pdf

12. Freire AB, Fernandes DL, Moro JS, Kneipp MM, Cardoso CM, Lima SBS. Serviços de urgência e emergência: quais os motivos que levam o usuário aos pronto-atendimentos? Saúde (Santa Maria) [Internet]. 2015 [acesso em 2017 abr 06];41(1):195-200. Disponível em: https://periodicos.ufsm.br/revistasaude/article/view/15061

13. Bugs TV, Rigo DFH, Bohrer CD, Borges F, Oliveira JLC, Tonini NS. Dificuldades do enfermeiro no gerenciamento da unidade de pronto-socorro hospitalar. Rev Enferm UFSM [Internet]. 2017 [acesso em 2017 dez 27];7(1):90-9. Disponível em: https://periodicos.ufsm.br/reufsm/article/view/23374/pdf

14. Figueiredo NMA, Machado WCA, organizadores. Corpo \& Saúde: condutas clínicas de cuidar. Rio de Janeiro: Águia Dourada; 2009.

15. Oliveira TR, Simões SMF. A comunicação enfermeira-cliente no cuidado em unidade de pronto atendimento 24h (UPA 24h): uma interpretação em Travelbee. Enferm Glob [Internet]. 2013 [acesso em 2017 nov 27];30:91-105. Disponível em: http://scielo.isciii.es/pdf/eg/v12n30/pt_clinica5.pdf

16. Broca PV, Ferreira MA. A equipe de Enfermagem e a comunicação não verbal. REME Rev Min Enferm [Internet]. 2014 [acesso em 2017 nov 27];18(3):697-702. Disponível em: http://www.reme.org.br/exportar-pdf/956/en_v18n3a14.pdf

17. Moreira AGM, Azevedo AL, Figueiredo NMA, Oliveira LFD, Araújo STC. Comportamento proxêmico da enfermagem no espaço da hemodiálise. Acta Paul Enferm [Internet]. 2017 [acesso em 2017 nov 27];30(4):343-9. Disponível em: http://www.scielo.br/pdf/ape/v30n4/0103-2100-ape-30-04-0343.pdf

18. Cavalcanti ACD, Coelho MJ. The responses to nursing care in cardiac surgery. Rev Enferm UFPE [Internet]. 2011 [acesso em 2017 jun 15];5(8):1891-7. Disponível em: http://www.revista.ufpe.br/revistaenfermagem/index.php/revista/article/viewArticle/1808

19. Amorim RKFCC, Silva MJP. Opinião de docentes de enfermagem sobre a efetividade da comunicação não verbal durante a aula. Acta Paul Enferm [Internet]. 2014 [acesso em 2017 jun 15];27(3):194-9. Disponível em: http://www.scielo.br/scielo.php?pid=S010321002014000300194\&script=sci_abstract\&tlng=pt 
20. Soares MZV, Bitencourt JVOV, Parker AG, Borges AMF, Vargas MAO, Schoeller SD. A influência do toque no cuidado às crianças especiais. Rev Enferm UFSM [Internet]. 2014 [acesso em 2017 nov 27];4(1):76-86. Disponível em: https://periodicos.ufsm.br/reufsm/article/view/10036/pdf

21. Rezende RC, Oliveira RMP, Araújo STC, Guimarães TCF, Santo FHE, Porto IS. Expressões corporais no cuidado: uma contribuição a comunicação da enfermagem. Rev Bras Enferm [Internet]. 2015 [acesso em 2017 jun 15];68(3):490-6. Disponível em: http://www.scielo.br/pdf/reben/v68n3/0034-7167-reben-68-030490.pdf

22. Cavalcanti ACD, Coelho MJ. Ways of care in cardiac sugery. Rev Pesqui Cuid Fundam [Internet]. 2011 [acesso em 2017 maio 22];3(4):2546-56. Disponível em: http://www.seer.unirio.br/index.php/cuidadofundamental/article/view/1399/pdf_462

23. Thofehrn MB, Montesinos MJL, Arrieira IC, Àvila VC, Vasques TCS, Farias ID. Processo de trabalho dos enfermeiros de um hospital da Espanha: ênfase nas tecnologias do cuidado. Cogitare Enferm [Internet]. 2014 [acesso em 2017 nov 27];19(1):141-6. Disponível em: http://revistas.ufpr.br/cogitare/article/view/35972/22180

24. Silva EPS, Carreiro MA, Gomes RC. Metodologia para identificação de Staphylococcus sp. na superfície do colchão da maca no pronto socorro. Rev Pró-UniverSUS [Internet]. 2016 [acesso em 2017 ago 08];07(3):15-9. Disponível em: http://editorauss.uss.br/index.php/RPU/article/view/658/384

\section{Autor correspondente}

Thiago Augusto Soares Monteiro da Silva

E-mail: thiagoams@bol.com.br

Endereço: Rua Pedro Alves Ferreira da Costa, №10, Casa № 1, Bairro - Madruga, Vassouras.

CEP: $27700-000$

\section{Contribuições de Autoria}

Autor 1 - Elaboração da introdução, metodologia, coleta de dados, análise e discussão dos resultados. Elaboração das considerações finais.

Autor 2 - Elaboração da análise e discussão dos resultados. Revisão da tipologia de cuidar/cuidados de Enfermagem.

Autor 3 - Elaboração da metodologia, coleta de dados, análise e discussão dos resultados. Elaboração das considerações finais.

\section{Como citar este artigo}

Silva TASM, Coelho MJ, Figueiredo NMA. Semiologia das expressões corporais dos enfermeiros no cotidiano do serviço de emergência. Rev. Enferm. UFSM. 2019 [Acesso em: 2019 jun 15];vol.9 e38:p1-19. DOI:https://doi.org/10.5902/2179769229882 